\title{
Prolonged but partial impairment of the hypoglycaemic physiological response following short-term hypoglycaemia in normal subjects
}

\author{
E. George ${ }^{1}$, N.Harris ${ }^{2}$, C. Bedford ${ }^{3}$, I. A. Macdonald ${ }^{4}$, C. A. Hardisty ${ }^{3}$, S. R. Heller ${ }^{3}$ \\ ${ }^{1}$ Academic Division of Medicine, University of Sheffield, UK \\ ${ }^{2}$ Department of Medical Physics, Royal Hallamshire Hospital, Sheffield, UK \\ ${ }^{3}$ Department of Diabetes and Endocrinology, Northern General Hospital, Sheffield, UK \\ ${ }^{4}$ Department of Physiology and Pharmacology, University of Nottingham Medical School, Nottingham, UK
}

\begin{abstract}
Summary Recent studies have reported reduced endocrine and symptomatic responses to hypoglycaemia 18-24 $\mathrm{h}$ after antecedent hypoglycaemia in both non-diabetic subjects and those with insulin-dependent diabetes mellitus. We examined these and peripheral physiological responses in eight nondiabetic subjects aged 23-35 years in the week following antecedent hypoglycaemia. Blood glucose levels were held at plateaus of $5 \mathrm{mmol} / \mathrm{l}$ and $2.5 \mathrm{mmol} / \mathrm{l}$ for $30 \mathrm{~min}$ during hyperinsulinaemic $\left(60 \mathrm{mU} \cdot \mathrm{m}^{-2}\right.$. $\min ^{-1}$ ) morning clamps on days 1,3 and 8 of two study periods separated by at least 4 weeks. Measurements were made at time 0,15 and 30 min of each plateau on each day. On the afternoon of Day 1 we also induced either euglycaemia with a blood glucose level of $5 \mathrm{mmol} / 1$ (control week) or hypoglycaemia of $2.9 \mathrm{mmol} / 1$ (hypo week) for $2 \mathrm{~h}$ in random order. The adrenaline response to morning hypoglycaemia $(p<0.01$ on all days) was attenuated on Day 3
\end{abstract}

$(p<0.05)$ and Day $8(p<0.05)$ compared to Day 1 of hypo week only. Sweating was also attenuated on Day $3(p<0.05)$ and Day $8(p<0.02)$ of hypo week only. Noradrenaline levels and tremor increased during hypoglycaemia on each study day $(p<0.05)$ but did not differ between days in either week. During hypo week only, the total symptom score response to hypoglycaemia was attenuated on Day $3(p<0.03)$ but not Day $8(p=0.10)$. Autonomic symptoms were similarly affected. In summary, the physiological responses to hypoglycaemia are affected differentially by antecedent hypoglycaemia with sweating and adrenaline responses remaining impaired for at least 5 days. [Diabetologia (1995) 38: 1183-1190]

Key words Antecedent hypoglycaemia, catecholamines, counterregulation, hypoglycaemia, hypoglycaemia unawareness.
The findings of the Diabetes Control and Complications Trial have highlighted not only the benefits but also the risks of tight glycaemic control with severe hypoglycaemic episodes occurring three times more frequently in the intensively treated group $[1,2]$. Hypoglycaemia is common due to inappropriate hyper-

Received: 18 November 1994 and in revised form: 3 March 1995

Corresponding author: Dr. S.R.Heller, Diabetes Centre, Northern General Hospital, Herries Road, Sheffield S5 7AU, $\mathrm{UK}$

Abbreviations: RMS, Root mean square; RIA, radioimmunoassay; AUC, area under curve; IDDM, insulin dependent diabetes mellitus; hypo, hypoglycaemia. insulinaemia and acquired impairments in the physiological mechanisms which defend the body against hypoglycaemia [3, 4]. These defences include not only the release of counterregulatory hormones which can restore blood glucose to normal levels [5] but also peripheral physiological responses which produce warning symptoms of impending hypoglycaemia [6]. Loss of hypoglycaemia awareness is associated with a diminished physiological response to hypoglycaemia, particularly that produced by activation of the sympathoadrenal system [7, 8]. Patients who develop unawareness are at particular risk of severe hypoglycaemia especially during intensive insulin therapy [9].

It is not clear why only some patients develop hypoglycaemia unawareness, although important fac- 


\begin{tabular}{|c|c|c|c|}
\hline \multicolumn{4}{|c|}{ Hypo week } \\
\hline & Day 1 & Day 3 & Day 8 \\
\hline A.M. & Clamp & Clamp & Clamp \\
\hline$\overline{P . M}$ & $\begin{array}{l}2 \mathrm{~h} \text { at } \\
\mathrm{mol} / \mathrm{gl}\end{array}$ & - & - \\
\hline
\end{tabular}

\begin{tabular}{|llll|} 
& Day 1 & $\begin{array}{c}\text { Control week } \\
\text { Day } 3\end{array}$ & Day 8 \\
\hline A.M. & Clamp & Clamp & Clamp \\
\hline P.M. & $\begin{array}{c}\text { 2h at } \\
5 \text { mmol/l glucose }\end{array}$ & - & - \\
\hline
\end{tabular}

Fig. 1. Diagram of the study design. All morning clamps were at 5 and $2.5 \mathrm{mmol} / 1$ plateaus for $30 \mathrm{~min}$ each. Study weeks were at least 4 weeks apart

tors include a long disease duration [10] and tight glycaemic control $[11,12]$. We have previously shown that a brief period of mild hypoglycaemia causes reduced counterregulatory and symptomatic responses to subsequent hypoglycaemia in normal subjects [13] and this has now been observed after overnight hypoglycaemia [14] and in patients with insulin-dependent diabetes mellitus (IDDM) [15]. This short-term adaptation to antecedent hypoglycaemia may partly explain the association of hypoglycaemia unawareness with intensified insulin therapy [12], although the duration of adaptation remains unknown. Previous studies have not examined the relationship between hypoglycaemic symptoms and objective measurements of the peripheral physiological response following antecedent hypoglycaemia. Thus, the aim of our study was to measure the effect of antecedent hypoglycaemia on the peripheral physiological, endocrine and symptomatic response to hypoglycaemia after 2 and 7 days.

\section{Subjects and methods}

Subjects. Eight non-diabetic subjects (seven male, one female) gave written consent to participate in this study which was approved by the Research ethics committee of the Northern General Hospital Trust, Sheffield, UK. Their mean age was 26 years (range 23-35) with a mean body mass index \pm SEM of $22.5 \pm 0.5 \mathrm{~kg} / \mathrm{m}^{2}$. They had no family history of diabetes and were using no medication.

Study design. Each subject was studied during two 8-day periods separated by at least 4 weeks (Fig. 1). After overnight fasting, hyperinsulinaemic hypoglycaemic clamps were performed on the mornings of days 1,3 and 8 of each study period. Human soluble insulin (Actrapid; Novo Laboratories, Copenhagen, Denmark) was infused at a fixed rate throughout $\left(60 \mathrm{mU} \cdot \mathrm{m}^{-2}\right.$. $\mathrm{min}^{-1}$ ) through a cannula placed in an antecubital vein of the non-dominant arm. Dextrose $(200 \mathrm{~g} / \mathrm{l})$ was given into the same vein using an IVAC 591 pump (IVAC, San Diego, Calif., USA). The infusion rate was adjusted at 5-min intervals according to blood glucose measurements obtained from a retrograde cannula inserted into a dorsal hand vein of the same arm, with the hand kept in a heated box at $55^{\circ} \mathrm{C}$. Blood glucose level was measured by a glucose oxidase method (Yellow Springs Instrument Co,, Yellow Springs, Ohio, USA).

After an initial 35-min run-in period, blood glucose was held at $5 \mathrm{mmol} / \mathrm{l}$ for $30 \mathrm{~min}$ and then allowed to fall over a further $35-\mathrm{min}$ period to a level of $2.5 \mathrm{mmol} / \mathrm{l}$. It was held at this level for a further $30 \mathrm{~min}$. Subjects were blinded to their blood glucose level at all times.

A further hyperinsulinaemic clamp $\left(80 \mathrm{mU} \cdot \mathrm{m}^{-2} \cdot \mathrm{min}^{-1}\right)$ was performed on the afternoon of Day 1 during each study period, with control and hypoglycaemia (HYPO) weeks distinguished by different interventions. On one occasion, we maintained the blood glucose level at $2.9 \mathrm{mmol} / \mathrm{l}$ for $2 \mathrm{~h}$ (interval hypo stimulus) and on the other, $5 \mathrm{mmol} / 1$ (interval control stimulus) for the same period. These were performed in random order.

At times 0,15 and $30 \mathrm{~min}$ of the $5 \mathrm{mmol} / 1$ and $2.5 \mathrm{mmol} / \mathrm{l}$ plateaus during morning experiments, we made the following measurements.

Physiological measurements. Blood pressure and pulse were assessed by means of an Accutorr sphygmomanometer (Datascope Medical Co. Ltd, Huntingdon, Herts., UK) employing an automated oscillatory analysis method with the cuff sited on the dominant arm.

Rates of sweating were measured using a $25-\mathrm{cm}^{2}$ ventilated chamber placed on the lower sternum. Flow rate through the chamber was maintained at 1 litre/min. The difference in humidity between the inflowing and outflowing air was measured using a surface resistance humidity sensor (Phys-Chemical Research Corporation, New York, N. Y., USA). Calculation of rate of water loss was based on measurements of humidity and ambient temperature as previously described [16].

Finger tremor was measured using a ring accelerometer consisting of a bimorph piezo electric element (Radio Spares, Corby, Northants, UK) loaded with a $56-\mathrm{mg}$ weight. The element was mounted horizontally inside a $50 \times 10-\mathrm{mm}$ plastic tube attached at one end to a small metal plate. The accelerometer was placed on the index finger of the non-dominant hand and finger tremor measured over a $1-\min$ period with the hand held outstretched and the forearm supported [17]. The signal from the transducer was amplified and filtered (5$20 \mathrm{~Hz}$ bandpass with a 12 decibel/octave roll-off) and the output digitised at a rate of 200 samples/s using an Amplicon PC26AT 12 bit A/D convertor (Amplicon Liveline, Brighton, Sussex, UK) attached to a notebook computer. The tremor signal was displayed on the computer and the root mean square (RMS) voltage of the tremor signal calculated over the 1-min measurement period.

Symptom scores. Symptom scores [18] were obtained by asking subjects to rate a series of individual symptoms from 1 (not present) to 7 (very severe). Symptoms described were: sweating, tremor, palpitations, warmth (autonomic); difficulty speaking, confusion, dizziness (neuroglycopenic); itching (dummy). Symptoms were listed in random order on each sheet used.

Endocrine measurements. A 5-ml sample of blood was added to a lithium-heparin tube containing $0.1 \mathrm{ml}$ of EGTA-glutathione and after separation, the plasma was stored at $-80^{\circ} \mathrm{C}$. Plasma adrenaline and noradrenaline were analysed by high performance liquid chromatography with electrochemical detection [19]. Coefficients of variation for the assays were 8 and $4 \%$, respectively.

A 5-ml sample of blood was added to a plain tube and allowed to clot at room temperature. It was then centrifuged and the plasma stored at $-80^{\circ} \mathrm{C}$. Total plasma insulin was measured using a double-antibody RIA method [20]. 

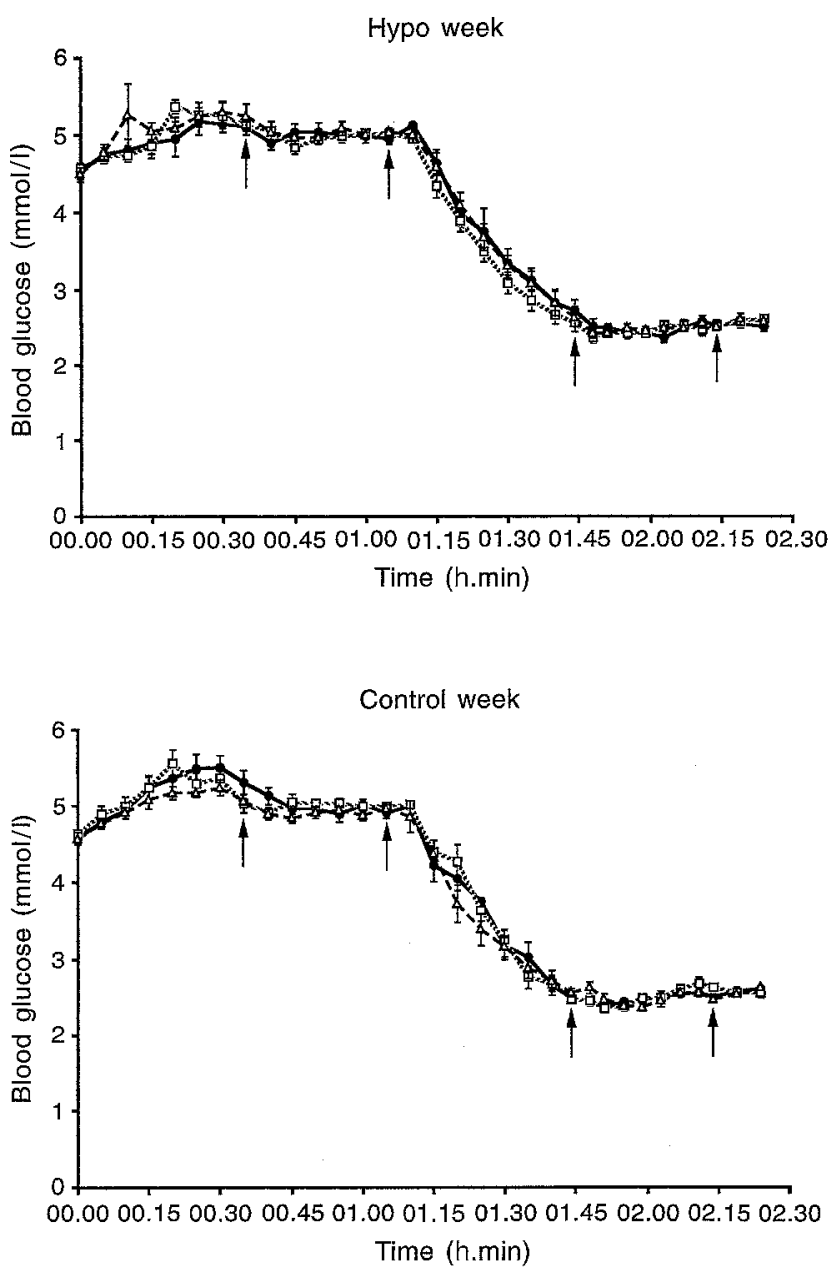

Fig. 2. Arterialised-venous whole blood glucose level during morning hyperinsulinaemic clamps on Day $1(\bullet)$, Day 3 ( $\square)$ and Day $8(\triangle)$ of hypo week (upper) and control week (lower). Arrows indicate the 30 -min measurement periods at blood glucose level of $5 \mathrm{mmol} / \mathrm{l}$ and $2.5 \mathrm{mmol} / \mathrm{l}$

\section{Statistical analysis}

Measurements made at 0,15 and $30 \mathrm{~min}$ at each glucose level were integrated by calculating areas under the curve (AUC) [21]. We calculated the difference in the AUC at 5 and $2.5 \mathrm{mmol} / 1$ for each experimental day and compared results on different days by paired Student's $t$-test using transformed data (square roots) for non-normal distributions. A $p$-value of less than 0.05 was regarded as significant.

\section{Results}

Results are expressed as mean \pm SEM unless otherwise indicated. The study period in which the afternoon interval stimulus induced on Day 1 was hypoglycaemia is referred to as hypo week. The study period in which the afternoon interval stimulus induced on Day 1 was euglycaemia is designated as the control week.

\section{Glucose and insulin}

Glucose values during the afternoon clamps. Mean whole blood glucose concentrations measured at 5min intervals over a 2 -h period were $4.98 \pm 0.02$ $\mathrm{mmol} / \mathrm{l}$ during afternoon euglycaemia and $2.90 \pm$ 0.01 during afternoon hypoglycaemia.

Glucose and insulin values during the morning clamps. The mean glucose concentrations achieved during the 30-min morning hypoglycaemic plateaus were similar on all study days (Fig.2).

Steady-state plasma insulin concentrations were similar in all studies during morning euglycaemic and hypoglycaemic plateaus. The concentrations during euglycaemia and hypoglycaemia, respectively in the control week were (in mU/l): Day 1, 120.0 \pm 5.5 and 119.8 \pm 5.1 ; Day 3, $114.9 \pm 4.0$ and $109.5 \pm 4.2$; Day 8, 121.9 \pm 5.1 and $114.3 \pm 5.3$. The corresponding hypo week values were (in $\mathrm{mU} / \mathrm{l}$ ): Day 1 , $116.4 \pm 5.8$ and $118.8 \pm 5.4$; Day $3,113.8 \pm 3.9$ and $114.2 \pm 4.1$; Day 8, $117.9 \pm 4.8$ and $112.3 \pm 4.4$.

\section{Catecholamines}

Adrenaline levels (Tables 1 and 2, Fig.3) rose significantly during hypoglycaemia on each study day $(p<0.01)$. During the control week, compared with Day 1 (AUC $71.9 \pm 9.0 \mathrm{pmol} \cdot \mathrm{min}^{-1} \cdot \mathrm{ml}^{-1}$ ) there was no significant change in the adrenaline response to hypoglycaemia on Day $3\left(68.4 \pm 5.2 \mathrm{pmol} \cdot \mathrm{min}^{-1}\right.$. $\left.\mathrm{ml}^{-1}, p=0.76\right)$ or Day $8\left(58.2 \pm 7.8 \mathrm{pmol} \cdot \mathrm{min}^{-1}\right.$. $\left.\mathrm{ml}^{-1}, p=0.27\right)$. During the hypo week, compared with the response on Day $1\left(86.4 \pm 18.0 \mathrm{pmol} \cdot \mathrm{min}^{-1}\right.$

Table 1. Rise in area under the curve during clamped hypoglycaemia

\begin{tabular}{|c|c|c|c|c|c|c|}
\hline & \multicolumn{3}{|l|}{ Hypo week } & \multicolumn{3}{|l|}{ Control week } \\
\hline & Day 1 & Day 3 & Day 8 & Day 1 & Day 3 & Day 8 \\
\hline Adrenaline $\left(\mathrm{pmol} \cdot \mathrm{min}^{-1} \cdot \mathrm{ml}^{-1}\right)$ & $86.4 \pm 18.0$ & $43.7 \pm 455.6^{\mathrm{a}}$ & $55.5 \pm 9.7^{\mathrm{a}}$ & $71.9 \pm 9.0$ & $68.4 \pm 5.2$ & $58.2 \pm 7.8$ \\
\hline Water loss $\left(\mathrm{g} \cdot \mathrm{min}^{-1} \cdot \mathrm{m}^{-2} \cdot \mathrm{h}^{-1}\right)$ & $3399 \pm 1004$ & $1286 \pm 602^{\mathrm{a}}$ & $1378 \pm 648^{b}$ & $3035 \pm 1143$ & $2446 \pm 51058$ & $1752 \pm 840$ \\
\hline Finger tremor (RMS volts/min) & $8.3 \pm 1.1$ & $7.1 \pm 1.3$ & $8.6 \pm 1.4$ & $6.8 \pm 4.2$ & $11.6 \pm 3.8$ & $9.1 \pm 1.7$ \\
\hline Total symptoms (scores/min) & $144.4 \pm 40.0$ & $74.1 \pm 20.1^{\mathrm{a}}$ & $120.0 \pm 4531.2$ & $136.9 \pm 46.6$ & $98.4 \pm 34.4$ & $109.7 \pm 37.6$ \\
\hline Autonomic symptoms (scores/min) & $102.2 \pm 3.6$ & $55.3 \pm 2.6^{\mathrm{a}}$ & $84.3 \pm 53.2$ & $99.4 \pm 3.5$ & $75.9 \pm 3.1$ & $86.3 \pm 3.3$ \\
\hline
\end{tabular}

${ }^{a} p<0.05$ compared to Day $1 ;{ }^{b} p<0.02$ compared to Day 1 . Results expressed as change in area under the curve (SEM) 
Table 2. Difference between study days of physiological responses during clamped hypoglycaemia

\begin{tabular}{|c|c|c|c|c|}
\hline & \multicolumn{2}{|l|}{ Hypo week } & \multicolumn{2}{|l|}{ Control week } \\
\hline & Day 1-Day 3 & Day 1-Day 8 & Day 1-Day 3 & Day 1-Day 8 \\
\hline Adrenaline $\left(\mathrm{pmol} \cdot \mathrm{min}^{-1} \cdot \mathrm{ml}^{-1}\right)$ & $42.8^{\mathrm{a}}(13.6: 71.9)$ & $30.8^{\mathrm{a}}(6.5: 55.2)$ & $3.5(-18.4: 25.4)$ & $13.7(-8.5: 35.8)$ \\
\hline Water loss $\left(\mathrm{g} \cdot \mathrm{min}^{-1} \cdot \mathrm{m}^{-2} \cdot \mathrm{h}^{-1}\right)$ & $2113^{\mathrm{a}}(437: 3789)$ & $2021^{b}(713: 3329)$ & $589(-985: 2164)$ & $1283(-1028: 3594)$ \\
\hline Finger tremor (RMS volts $\cdot \mathrm{min}$ ) & $1.6(-1.6: 4.8)$ & $-0.2(-4.4: 4.0)$ & $-4.3(-11.8: 3.2)$ & $-2.3(-5.7: 1.2)$ \\
\hline Total symptoms (scores $\cdot \min$ ) & $70.3^{\mathrm{a}}(23.8: 116.8)$ & $24.4(-0.7: 49.5)$ & $38.4(-5.5: 82.4)$ & $27.2(-22.2: 76.6)$ \\
\hline Autonomic symptoms (scores $\cdot \min$ ) & $46.9^{\mathrm{a}}(13.1: 80.6)$ & $17.8(-5.7: 41.4)$ & $23.4(-0.9: 47.7)$ & $13.1(-25.1: 55.2)$ \\
\hline
\end{tabular}

Results are expressed as mean fall in AUC from Day 1 (Lower: Upper $95 \% \mathrm{Cl}$ ). ${ }^{\mathrm{a}} p<0.05 ;{ }^{\mathrm{b}} p<0.02$; for all other comparisons NS
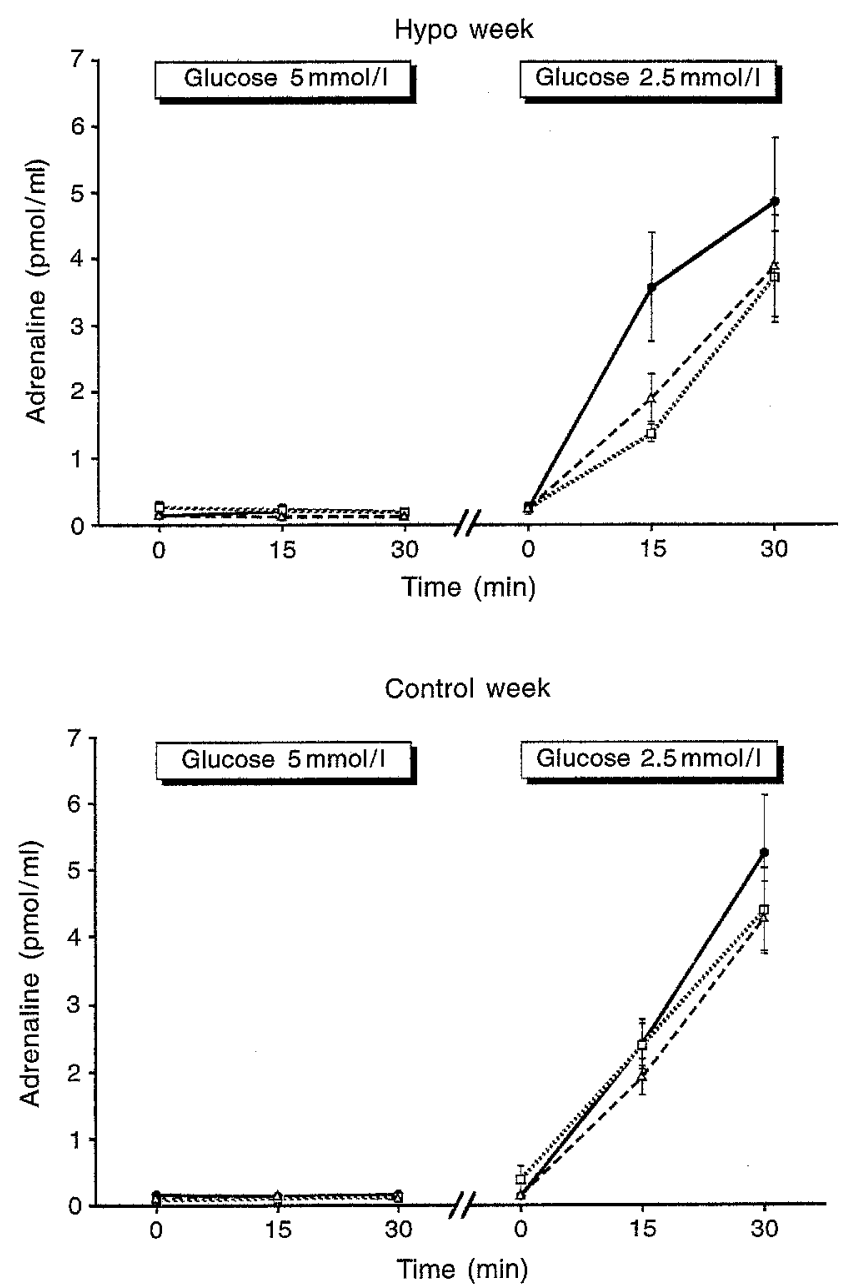

Fig.3. Adrenaline concentrations during morning hyperinsulinaemic clamps on Day $1(\bullet)$, Day $3(\square)$ and Day $8(\triangle)$ of hypo week (upper) and control week (lower). The response to hypoglycaemia, when compared to Day 1 , is attenuated on Day 3 and Day 8 of hypo week but not on Day 3 or Day 8 of the control week

$\mathrm{ml}^{-1}$ ), the response on Day 3 was reduced $\left(43.7 \pm 5.6 \mathrm{pmol} \cdot \mathrm{min}^{-1} \cdot \mathrm{ml}^{-1}, p<0.05\right)$ as was the response on Day $8 \quad\left(55.5 \pm 9.7 \mathrm{pmol} \cdot \mathrm{min}^{-1} \cdot \mathrm{ml}^{-1}\right.$, $p<0.05$ ).

Noradrenaline levels (Tables 1 and 2, Fig.4) rose significantly during morning hypoglycaemia on each study day $(p<0.05)$. During the control week, com- pared to the response on Day 1, no significant change in the noradrenaline response to morning hypoglycaemia was seen on Day 3 or Day 8. During the hypo week compared to Day 1 no change was seen in the response on Day 3 or Day 8.

Sweat responses. A significant rise in the sweating response to hypoglycaemia (Tables 1 and 2, Fig. 5) was seen on Day 1 of both the control week $(p<0.02)$ and hypo week $(p<0.05)$. During the control week comparisons with the Day 1 response (3035 \pm $1143 \mathrm{~g} \cdot \mathrm{min}^{-1} \cdot \mathrm{m}^{-2} \cdot \mathrm{h}^{-1}$ ) demonstrated no significant change in the sweat response to morning hypoglycaemia on Day $3\left(2446 \pm 1058 \mathrm{~g} \cdot \mathrm{min}^{-1} \cdot \mathrm{m}^{-2} \cdot \mathrm{h}^{-1}\right.$, $p=0.49)$ or Day $8\left(1752 \pm 840 \mathrm{~g} \cdot \mathrm{min}^{-1} \cdot \mathrm{m}^{-2} \cdot \mathrm{h}^{-1}\right.$, $p=0.31$ ). However, during hypo week comparison with the response on Day $1(3399 \pm 1004 \mathrm{~g} \cdot \mathrm{min}$ ${ }^{-1} \cdot \mathrm{m}^{-2} \cdot \mathrm{h}^{-1}$ ) demonstrated an attenuated response to

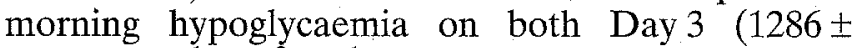
$\left.602 \mathrm{~g} \cdot \min ^{-1} \cdot \mathrm{m}^{-2} \cdot \mathrm{h}^{-1}, p<0.05\right)$ and Day $8(1378 \pm$ $\left.648 \mathrm{~g} \cdot \min ^{-1} \cdot \mathrm{m}^{-2} \cdot \mathrm{h}^{-1}, p<0.02\right)$.

Finger tremor. Finger tremor (Tables 1 and 2, Fig. 6) rose during morning hypoglycaemia on each study day $(p<0.05)$. However, the response did not change significantly on Day 3 or Day 8 compared to Day 1 in either study week.

Blood pressure and heart rate. Systolic pressure rose significantly during hypoglycaemia on Day 8 of hypo week only (data not shown).

No significant change in diastolic pressure was seen during hypoglycaemia on any study day in either study week (data not shown).

Heart rate rose significantly during hypoglycaemia on Days $1 \quad(p<0.001), 3 \quad(p<0.03)$ and Day 8 $(p<0.01)$ of hypo week and Day $1(p<0.01)$ of the control week (data not shown).

Symptom scores. Total symptom scores (Tables 1 and 2 , Fig. 7) rose during hypoglycaemia on each study day ( $p<0.05$ on all days). No significant change in the this response was seen between days in the control week. In hypo week, compared to Day 1 the response on Day 3 was attenuated $(p<0.03)$, but not 


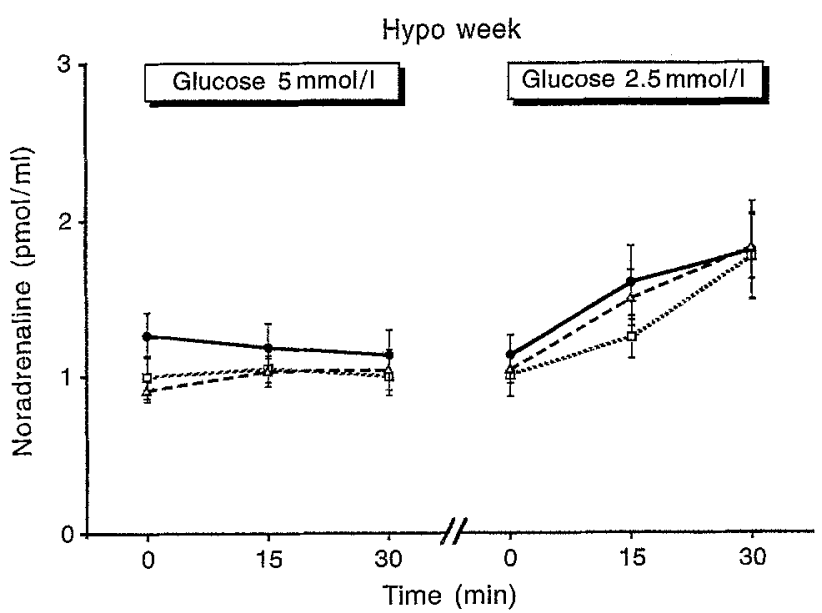

Control week

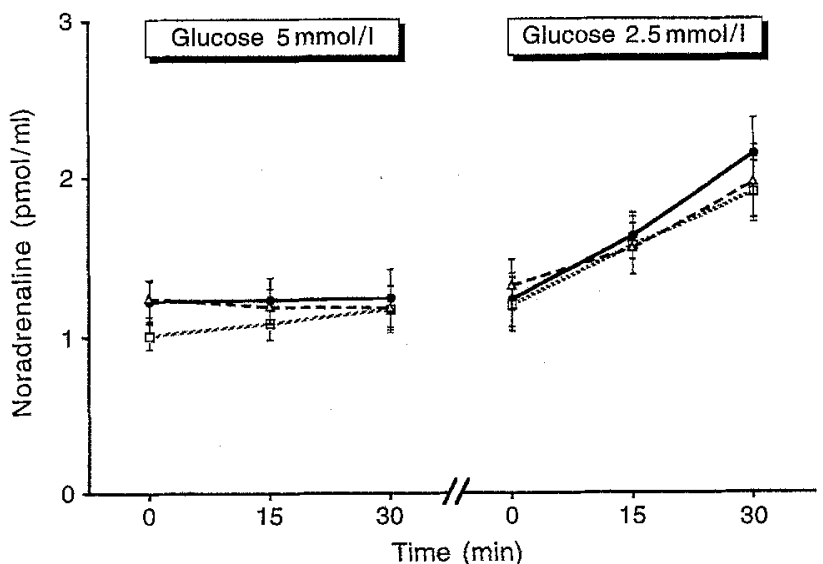

Fig. 4. Noradrenaline concentrations during morning hyperinsulinaemic clamps on Day $1(\bullet)$, Day $3(\square)$ and Day $8(\triangle)$ of hypo week (upper) and control week (lower). The response to hypoglycaemia, when compared to Day 1 , is not significantly altered on Day 3 and Day 8 of hypo week or on Day 3 or Day 8 of the control week

on Day $8(p=0.10)$. Autonomic symptoms (Tables 1 and 2) followed a similar pattern with attenuated rise on Day 3 compared to Day 1 of hypo week but not on Day 8.

Neuroglycopenic symptom scores (Tables 1 and 2) rose significantly only on Day 8 of hypo week. No significant changes in scores during hypoglycaemia were seen between study days in either study week.

None of the responses on Day 1 of hypo and control weeks were significantly different.

\section{Discussion}

Our data confirm previous studies in diabetic and normal subjects which have reported impairments in the symptomatic and counterregulatory hypoglycaemic response following antecedent hypoglycaemia [13-15, 22-24]. We have also measured pe-
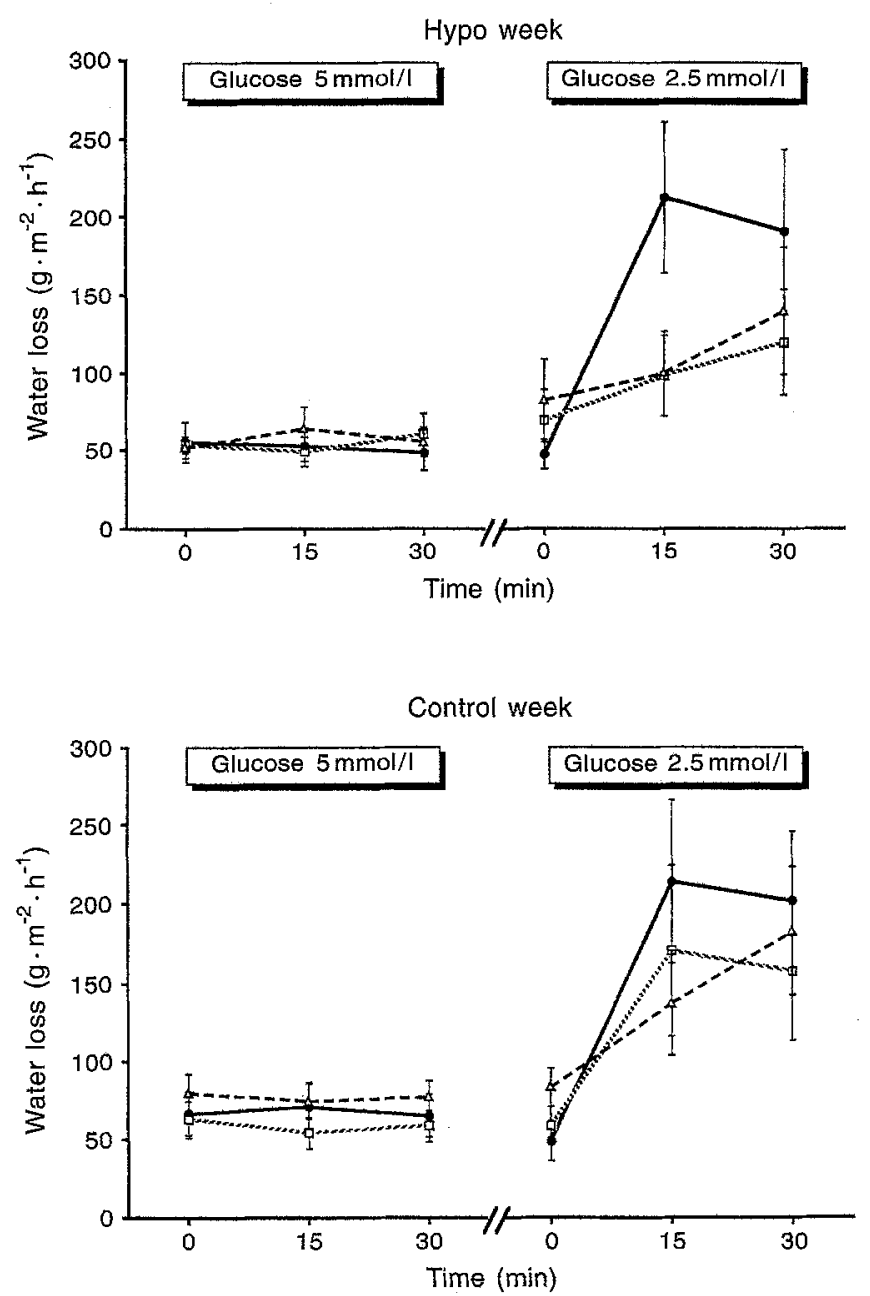

Fig.5. Rates of water loss during morning hyperinsulinaemic clamps on Day $1(\bullet)$, Day $3(\square)$ and Day $8(\triangle)$ of hypo week (upper) and control week (lower). The response to hypoglycaemia, when compared to Day 1, is attenuated on Day 3 and Day 8 of hypo week but not on Day 3 or Day 8 of the control week

ripheral physiological responses which allowed us to explore whether a reduced symptomatic response was either a consequence of diminished sympathoadrenal activation or a failure of subjects to recognise peripheral changes. The responses most affected by hypoglycaemia were those of adrenaline and sweating which were impaired 2 days after the initial hypoglycaemic episode and were still reduced after a week. However, we cannot be certain that the effect of antecedent hypoglycaemia lasts a full 7 days. A consequence of our study design was that the morning hypoglycaemic clamps used to test the physiology may themselves have affected the response they were measuring. Widom and Simonson [23] have shown that 1 -h periods of hypoglycaemia, repeated over 4 days produce an impaired counterregulatory and symptomatic response to subsequent hypoglycaemia. Thus, even the brief $30 \mathrm{~min}$ of hypoglycaemia on days 1 and 3 may have a cumulative effect in 

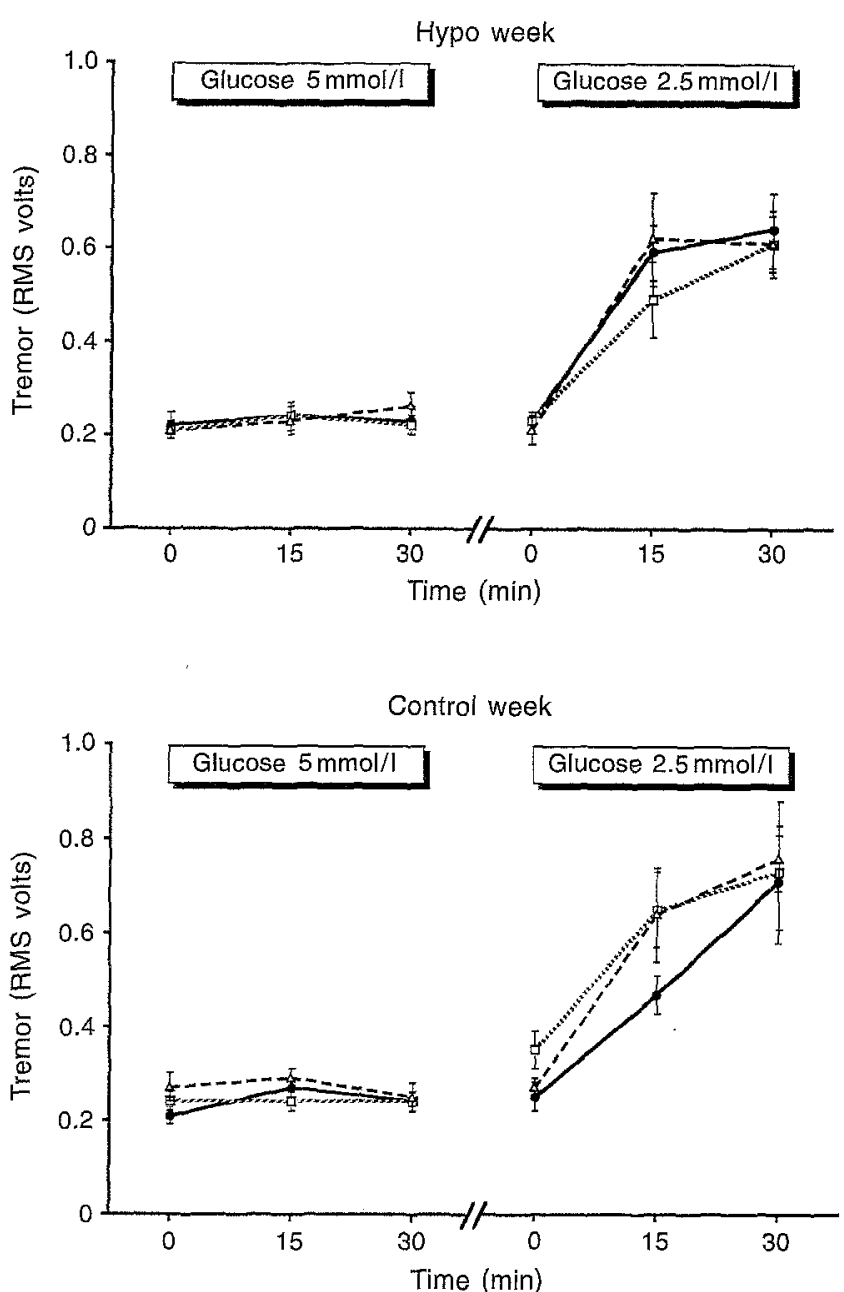

Fig. 6. Finger tremor response during morning hyperinsulinaemic clamps on Day $1(\bullet)$, Day $3(\square$ ) and Day $8(\triangle)$ of hypo week (upper) and control week (lower). The response to hypoglycaemia, when compared to Day 1, is not significantly different on Day 3 and Day 8 of hypo week or on Day 3 or Day 8 of the control week

addition to the $2 \mathrm{~h}$ of hypoglycaemia on the afternoon of Day 1. Nevertheless, since there was a 5-day gap before the response was tested again on Day 8 , we can conclude that sweating and adrenaline responses to subsequent hypoglycaemia remain impaired for at least 5 days following antecedent hypoglycaemia.

The data show that not all responses were affected equally. Measurements of tremor were unaffected by antecedent hypoglycaemia with similar responses recorded on each occasion they were tested. This could be because our method of recording tremor was not sufficiently sensitive to identify minor changes. However, since the equipment consistently recorded a significant increase during each period of hypoglycaemia we would expect it to detect an impaired response. Thus, there may be a differential effect of antecedent hypoglycaemia on the hypoglycaemic physiological response. Sweating is mediated by sympa-
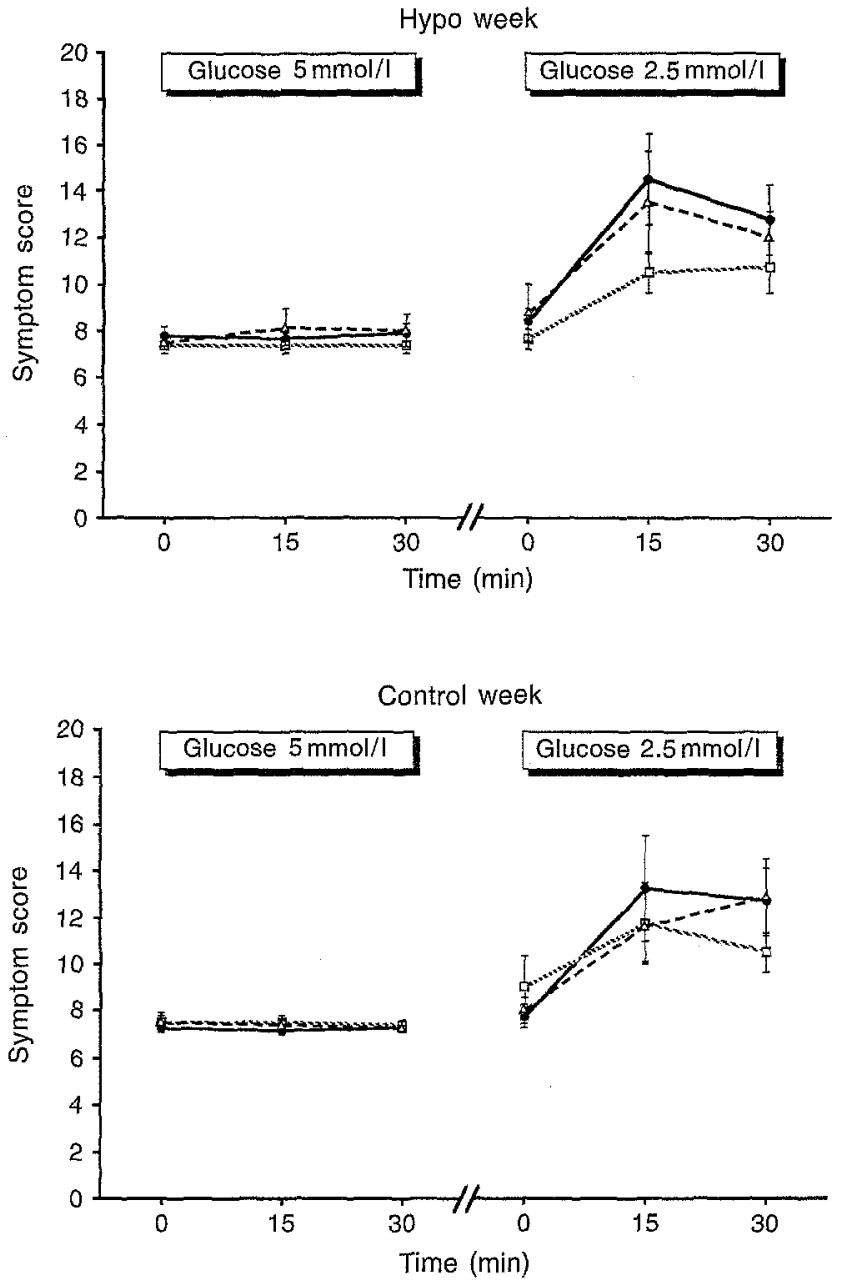

Fig. 7. Total symptom scores during morning hyperinsulinaemic clamps on Day $1(\bullet)$, Day $3(\square)$ and Day $8(\triangle)$ of hypo week (upper) and control week (lower). The response to hypoglycaemia, when compared to Day 1 , is attenuated on Day 3 but not on Day 8 of hypo week. No change is seen on Day 3 or Day 8 of the control week

thetic cholinergic fibres [25] while the tremor response is caused both by activation of sympathetic noradrenergic fibres and also by increases in circulating adrenaline [25]. The individual components of the physiological response to hypoglycaemia are activated at different glucose levels [26] and it is conceivable that some may be less affected by the depth or duration of antecedent hypoglycaemia than others. Alternatively, peripheral physiological responses may be equally impaired following hypoglycaemia but the rate at which various responses recover might differ.

The changes we observed in adrenaline and noradrenaline also support the notion of a differential response. Both adrenaline and noradrenaline concentrations normally increase during hypoglycaemia although the magnitude of the adrenaline response is disproportionately greater [27]. We found that although the adrenaline responses to hypoglycaemia 
were attenuated following antecedent hypoglycaemia at both Days 3 and 8, those of noradrenaline were unaffected. The increase in adrenaline during hypoglycaemia is secondary to adrenomedullary secretion activated centrally while increases in plasma noradrenaline probably reflect increased peripheral sympathetic activity and spillover from post-ganglionic neurons [27]. Hoffman et al. [28] have recently reported a dissociation between muscle sympathetic nerve activity and increases in adrenaline during hypoglycaemia and suggested that the responses may be independently mediated. It is of interest that the hypoglycaemic tremor response, which is in part mediated through activation of sympathetic noradrenergic neurons [25] was not significantly attenuated following antecedent hypoglycaemia while other components of the physiological response (such as sweating) mediated through other mechanisms were impaired.

The possibility of a differential recovery of impaired physiological responses to hypoglycaemia is supported by data from a recent study by DagogoJack et al. [29]. They report a restoration in the symptomatic response to hypoglycaemia among patients with IDDM who avoided hypoglycaemia for 3 months although the counterregulatory response remained unchanged. Clearly, further work is necessary to confirm whether antecedent hypoglycaemia causes differential impairments in the physiological response to subsequent hypoglycaemia.

Why should $2 \mathrm{~h}$ of hypoglycaemia modify responses for up to a week? Data from animal models have suggested possible mechanisms whereby cerebral tissue could adapt to repeated episodes of hypoglycaemia. Increased cerebral glucose utilisation has been demonstrated in rats rendered chronically hypoglycaemic [30] and attributed to increased numbers of glucose transporters or increased cerebral blood flow [31]. However, hypoglycaemia had to be maintained for weeks to demonstrate an effect, considerably longer than in our study. Boyle et al. [32] have recently shown that $56 \mathrm{~h}$ of mild hypoglycaemia increases brain glucose uptake in non-diabetic humans, which is maintained when blood glucose is lowered and this adaptation could explain the diminished responses we observed. Nevertheless, $56 \mathrm{~h}$ is still far longer than the $2 \mathrm{~h}$ of hypoglycaemia we induced in our study and there has been no demonstration of changes in cerebral glucose utilisation or transport following brief hypoglycaemic episodes. Thus, the mechanisms which underly the prolonged alteration in response following short-term hypoglycaemia remain unknown.

In summary, we have demonstrated in non-diabetic subjects that while some components of the physiological response to hypoglycaemia are attenuated for at least 5 days following $2 \mathrm{~h}$ of hypoglycaemia, others are apparently unaffected. A differential response to antecedent hypoglycaemia may offer clues to its pathogenesis and suggest clinical approaches to mitigate its effect among those with diabetes.

Acknowledgements. E.G. was supported by a Project Grant from the British Diabetic Association. We are also grateful for financial support from the Research Committee of the Northern General Hospital and The Special Trustees, Central Sheffield Hospitals. We thank S. Baikushev, Ms. L. Ashworth and the nurses of the Programmed Investigation Unit of the Northern General Hospital for technical assistance.

\section{References}

1. The Diabetes Control and Complications Trial Research Group (1993) The effect of intensive treatment of diabetes on the development and progression of long-term complications in insulin-dependent diabetes mellitus. $\mathrm{N}$ Engl J Med 329: 977-986

2. The Diabetes Control and Complications Trial Research Group (1991) Epidemiology of severe hypoglycemia in DCCT. Am J Med 90: 450-459

3. Bolli GB, De Feo P, Compagnucci P et al. (1983) Abnormal glucose counterregulation in IDDM. Interaction of anti-insulin antibodies and impaired glucagon and epinephrine secretion. Diabetes 32: 134-141

4. Cryer PE, Fisher JN, Shamoon H (1994) Hypoglycaemia. Diabetes Care 17: 734-755

5. Cryer PE (1993) Glucose counterregulation: the prevention and correction of hypoglycemia in humans. Am J Physiol 264: E149-E155

6. Heller SR, Macdonald IA (1991) Physiological disturbances in hypoglycaemia: effect on subjective awareness. Clin Sci 81: 1-9

7. Heller SR, Macdonald IA, Herbert M, Tattersall RB (1987) Influence of sympathetic nervous system on hypoglycaemic warning symptoms. Lancet II: 359-363

8. Hepburn DA, Patrick AW, Brash HM, Thomson I, Frier BM (1991) Hypoglycaemia unawareness in type 1 diabetes: a lower plasma glucose in required to stimulate sympathoadrenal activation. Diabet Med 8: 934-945

9. Gold AE, MacLeod KD, Frier BM (1994) Frequency of severe hypoglycaemia in insulin-dependent diabetic patients with altered awareness of hypoglycemia. Diabetes Care 17: 697-703

10. Pramming S, Thorsteinsson B, Bendtson I, Binder C (1991) Symptomatic hypoglycaemia in 411 type 1 diabetic patients. Diabet Med 8: 217--222

11. Amiel SA, Sherwin RS, Simonson DC, Tamborlane WV (1988) Effect of intensive insulin therapy on glycemic thresholds for counterregulatory hormone release. Diabetes 37: 901-907

12. Cryer PE (1992) Iatrogenic hypoglycemia as a cause of hypoglycaemia-associated autonomic failure in IDDM: a vicious cycle. Diabetes 41: 255-260

13. Heller SR, Cryer PE (1991) Reduced neuroendocrine and symptomatic responses to subsequent hypoglycemia after 1 episode of hypoglycemia in nondiabetic humans. Diabetes 40: 223-226

14. Veneman T, Mitrakou A, Mokan M, Cryer PE, Gerich JE (1993) Induction of hypoglycemia unawareness by asymptomatic nocturnal hypoglycemia. Diabetes 42: 1233-1237

15. Dagogo-Jack SE, Craft S, Cryer PE (1993) Hypoglycemiaassociated autonomic failure in insulin-dependent diabetes mellitus. J Clin Invest 91: 819-828 
16. Smallwood RH, Thomas SE (1985) An inexpensive portable monitor for measuring evaporative water loss. Clin Phys Physiol Meas 6: 2: 147-154

17. Birmingham AT, Wharrad HJ, Williams EJ, Wilson CG (1985) Accelerometric measurements of finger tremour: analysis of the analogue signal. J Physiol (Lond) 361: 12P(Abstract)

18. Hepburn DA, Deary IJ, Frier BM, Patrick AW, Quinn JD, Fisher BM (1991) Symptoms of acute hypoglycaemia in humans with and without IDDM (factor analysis approach). Diabetes Care 14: 949-957

19. Macdonald IA, Lake DM (1985) An improved technique for extracting catecholamines from body fluids. J Neuroscience Meth 13: 239-240

20. Soeldner JS, Slone D (1965) Critical variables in the RIA of serum insulin using the double antibody system. Diabetes 14: 771-779

21. Matthews JNS, Altman DG, Campbell MJ, Royston P (1990) Analysis of serial measurements in medical research. BMJ 300: 230-235

22. Davis M, Shamoon H (1991) Counterregulatory adaptation to recurrent hypoglycemia in normal humans. J Clin Endocr Metab 73: 995-1001

23. Widom B, Simonson DC (1992) Intermittent hypoglycemia impairs glucose counterregulation. Diabetes 41: 1597-1602

24. Lingenfelser T, Renn W, Sommerwerck U et al. (1993) Compromised hormonal counterregulation, symptom awareness, and neurophysiological function after recurrent short term episodes of insulin-induced hypoglycemia in IDDM patients. Diabetes 42: 610-618
25. Macdonald IA, Maggs DG (1993) Cutaneous blood flow, sweating, tremour and temperature regulation in hypoglycaemia. In: Frier BM, Fisher BM (eds) Hypoglycaemia and diabetes. Edward Arnold, London, pp 132-143

26. Mitrakou A, Ryan C, Veneman Tet al. (1991) Hierarchy of glycemic thresholds for counterregulatory hormone secretion, symptoms and cerebral dysfunction. Am J Physiol 260: E67-E74

27. Cryer PE (1993) Glucose counterregulation: the physiological mechanisms that prevent or correct hypoglycemia. In: Frier BM (ed) Hypoglycaemia and diabetes. Edward Arnold, London, pp 34-55

28. Hoffman RP, Sinkey CA, Anderson EA (1994) Hypoglycemia increases muscle sympathetic nerve activity in IDDM and control subjects. Diabetes Care 17: 673-680

29. Dagogo-Jack SE, Rattarasarn C, Cryer PE (1994) Reversal of hypoglycemia unawareness, but not defective glucose counterregulation, in IDDM. Diabetes 43: 1426-1434

30. McCall AL, Fixman LB, Fleming N, Torneheim K, Chick W, Ruderman NB (1986) Chronic hypoglycemia increases brain glucose transport. Am J Physiol 251: E442-E447

31. McCall AL (1993) Effects of glucose deprivation on glucose metabolism in the central nervous system. In: Frier BM, Fisher BM (eds) Hypoglycaemia and diabetes. Edward Arnold, London, pp 56-71

32. Boyle PJ, Nagy RJ, O'Connor AM, Kempers SF, Yeo RA, Qualls C (1994) Adaptation in brain glucose uptake following recurrent hypoglycemia. Proc Natl Acad Sci USA 91: 9352-9356 